\title{
Boost Compensator for Predictive Current Mode Control of High Power Factor Boost Rectifier
}

\author{
K.Ramalingeswara Prasad \\ Asst.Professor \\ Dept.of Electrical and Electronics \\ Engineering, \\ LBRCE.,Mylavaram.
}

\author{
P.Deepak Reddy \\ Asst.Professor \\ Dept.of Electrical and Electronics \\ Engineering, \\ LBRCE.,Mylavaram.
}

\author{
Kranthi kiran Ankam \\ Asst.Professor \\ Dept.of Electrical and Electronics \\ Engineering, \\ LBRCE.,Mylavaram.
}

\begin{abstract}
This paper presents the design of the Boost compensator for a predictive current mode control of high power factor boost rectifier. The general features are no input voltage sensing, no use of multiplier, and no inner current loop regulator. The switching principle of the controller is predictive, as the actual current equals the reference current at the ending of the switching period. This switching law will extend the range of the continuous conduction mode (CCM) of operation. boost compensator is designed by using k-factor approach with the help of low frequency small signal model of the boost rectifier switched by the predictive current mode control. Simulation results on a $400 \mathrm{~W}$ boost rectifier are presented.
\end{abstract}

\section{Index terms}

Boost Regulator, CCM, Predictive current mode controller, small signal model, Boost compensator

\section{INTRODUCTION}

Conventional ac/dc power converters that are connected to the line through full-wave rectifier draws a non-sinusoidal input current. Harmonic current in a current waveform flowing through the impedances in the electrical utility distribution system can create harmonic voltages. These harmonics distort the local voltage waveform, potentially interfering with other electrical equipment connected to the same electrical service. This fact and the presence of standards or recommendations have forced to use power factor correction in power supplies.

Unity power factor and tight output voltage regulation are achieved by active power factor correction techniques. A single phase diode rectifier fallowed by boost converter with proper control forms a rectifier with active power factor correction (PFC) . The primary tasks of a controller for PFC circuits are to:

- Achieve high power factor during steady-state operation with a constant load;

- Maintain an output voltage waveform $v_{(}(t)$ around a specified average value $V_{o}(t)$ with low ripple;

The above both control goals can be achieved, if the controller forces the input current wave $i_{g}$ to have the same shape as the input voltage $v_{g}$ so that input impedance appears to be resistive, that rectifier is called a resistor emulator. With this objective, remarkable simplifications in the control structure of the PFC rectifier has been achieved by carrier controllers such as the linear peak current mode (LPCM) control and the nonlinear carrier (NLC)[2] control. The boost rectifier power circuit and the general controller structure of Predictive current mode controller is shown in Fig. 1.

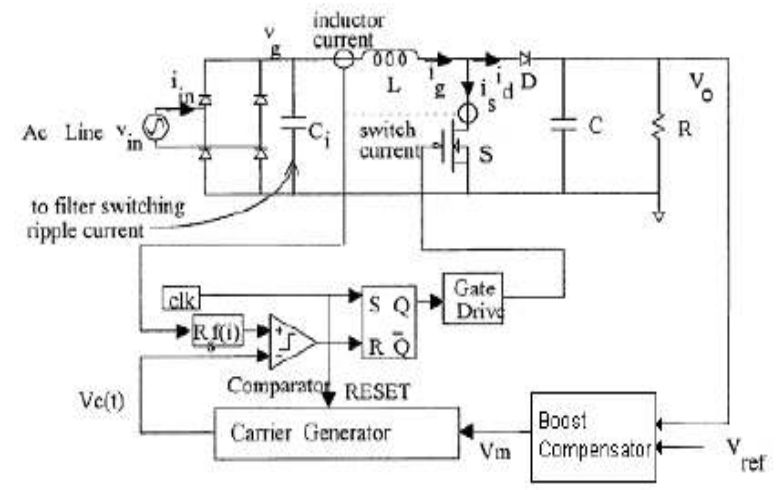

Fig.1. Power circuit of the single phase PFC rectifier with the generalized control structure of the NLC, the LPCM, and the Predictive current mode controller.

The inner loop current regulator is eliminated and input voltage sensing is not required in the Predictive current mode controller [1]. In effect, the duty ratio of the switch is calculated in the predictive current mode controller by solving an equation in the modulator. One side of the equation is a certain function of the sensed current (for example average of the switch current for the NLC) and the other side is the carrier waveform derived after processing the voltage regulator output. In the presented Predictive current mode controller, the switch is controlled in such a way that the estimated inductor current will be proportional to the rectified input voltage at the end of the switching period $(\mathrm{T})[1]$.

The estimation of the inductor current is possible since the input voltage is practically constant over a switching period. This enables us to predict the current ripple of the subsequent off period during the on time of the switch itself. The predicted off state ripple current can be added with the on state actual current to determine the current at the end of the switching period.

The advantage of the Predictive current mode controller is the extended range of continuous conduction mode of operation compared to NLC[1]. The Predictive current mode

controller has the structure of a standard current programmed controller with a compensating ramp that is nonlinear.

In this paper, after a brief review of the Predictive current mode control high power factor boost rectifier, boost compensator for voltage loop is designed. The goal is to improve the system dynamic performance. Simulation results, achieved using Matlab/Simulink software are presented. 


\section{PREDICTIVE CURRENT MODE CONTROLLER}

The generalized control objective of a high power factor boost rectifier can be expressed as

$$
f\left(i_{g}\right)=\frac{v_{g}}{R_{e}}
$$

$R \mathrm{e}$ is the emulated resistance of the rectifier and is a function of the inductor current. This function can be different for different control strategies. For example NLC implements average current mode control. In the case of LPCM, this function represents peak current of the inductor, $i_{g p}$, in every switching period Ts. In a switching period the current in the inductor reaches its peak at the end of the $\mathrm{ON}$ time $\mathrm{dT}_{\mathrm{s}}$, of the switch.In the Predictive current mode controller the duty ratio of the switch is controlled in such a way that the inductor current becomes proportional to the rectified input voltage at the end of each switching period. Therefore for Predictive current mode controller the function $f(i)$ is given by (2) $f\left(i_{g}\right)_{p s m}=i_{g}\left[T_{s}\right]$

It may be noted that the inductor current at the end of period is equal to the current at the beginning of the next period, or,

$i_{g}\left[T_{s}\right]_{k}=i_{g}[0]_{k+1}=\frac{v_{g}}{R_{e}}$ in CCM. Since that switching frequency of the converter is much higher than the frequency of the input voltage we can assume that the input and the output voltages are constant in a switching period. Therefore, when the converter is operating in CCM the slope of the turn-off current can be predicted during ON time of the switch itself. Then instead of (2), (3) can be used for Predictive current mode controller

$$
i_{g}\left[d T_{s}\right]_{k}=i_{s}\left[d T_{s}\right]_{k}=\frac{v_{g}}{R_{e}}+\left(\frac{V_{o}-v_{g}}{L}\right)(1-d) T_{s}
$$

The expression on the right-hand-side of (3) represents the predictive current trajectory, whose initial value is $\left(v_{g} / R_{e}\right)+\left(V_{0}-v_{g} / L\right) T_{s}$ and the slope is equal to $\left(V_{0}-v_{g} / L\right)$, the slope of the off state inductor current. In PSM the switch turns off when the actual current equals the predictive current trajectory or (3) is satisfied.

We can use the boost converter continuous conduction mode input to output conversion equation of (4) to replace $v_{g}$ in

(3) by $v_{o}$ and $\mathrm{d}$. Then we get (5) as the duty ratio control function for the PSM

$$
\begin{gathered}
v_{g}=(1-d) V_{0} \\
i_{g}\left[d T_{s}\right]=I_{r e f}(1-d)+\left(\frac{V_{0} T_{s}}{L}\right) d(1-d)
\end{gathered}
$$

where

$$
I_{r e f}=\frac{V_{0}}{R_{e}}=\frac{v_{m}}{R_{s}}
$$

$\mathrm{R}_{\mathrm{s}}$ is the current sense resistance of the converter and $v_{m}$ is the input voltage to the modulator. Under closed loop operation is obtained as the output of the voltage error amplifier loop. In [2] and [3], the right-hand-side expressions of (5) is converted into suitable carrier waveforms by replacing the duty ratio term $d$ by $t / T_{s}$

$$
\begin{gathered}
I_{c}=\frac{V_{c}(t)}{R_{s}} \\
=I_{r e f}\left(1-\frac{t}{T_{s}}\right)+\left(\frac{V_{0} T_{s}}{L}\right) \frac{t}{T s}\left(1-\frac{t}{T_{s}}\right)
\end{gathered}
$$

In the Predictive current mode controller the switch is turned on at the beginning of every switching period and turned off when the duty ratio is such that the condition given by (7) is satisfied. Current mode control may exhibits a steady state stability problem under certain condition because of the presence of local feed back in its control structure. In Predictive current mode controller, the distortion near the peak of the waveform is present at the particular operating conditions due to the violation of steady state condition [1]. The distortion in the input current waveform does not spread over the entire line half cycle instead it gradually reduces in the region in which $K>M_{g}^{2}\left(m_{g}-M_{g} \frac{4}{3 \pi}\right)$

\section{LOW FREQUENCY SMALL SIGNAL MODEL AND BOOST COMPENSATOR.}

In this section, we would like to develop a linear, low frequency, small-signal model of the boost rectifier switched by the Predictive current mode controller. In a line cycle, the rectified input voltage varies from 0 to $v_{g m}$. Under steady-state condition the inductor current $i_{g}$ is proportional to rectified input voltage and the volt-second balance for the boost inductor occurs at every switching period $\left(\mathrm{T}_{\mathrm{s}}\right)$.

However, the instantaneous input power $v_{g} i_{g}$ equals the output power $V_{o}^{2} / R$ only at the period in which rectified input voltage is $v_{g m} / \sqrt{2}$. We therefore choose this switching period as the equivalent nominal operating point that represents the entire line cycle for the derivation of the small-signal model. The variables are expressed by capital letters (nominal as well as DC) and small-signal deviations by $\left({ }^{\wedge}\right)$ on the top of the symbol. The control structure shown in Fig.. is that of a current mode controller. So the control gain transfer function is derived in two steps [3], [4].First, the low-frequency small-signal model of the boost converter is obtained in the standard form in terms of duty ratio perturbation $\hat{D}$ as the control input. Subsequently the smallsignal model of the modulator is derived in order to replace $\hat{D}$ by the perturbations in the error amplifier output voltage $\hat{V}_{m}$ and other state variables $\hat{V}_{0}$ and $\hat{I}_{g}$. From these two steps the low frequency small signal model is given by (8) [1]: 
$\left.\left[\begin{array}{c}\frac{\hat{d}_{g}}{d t} \\ \frac{d \hat{V}_{0}}{d t}\end{array}\right]=\left[\begin{array}{cc}\frac{-R_{s}}{L N} & \frac{-(1-D)}{L}+\frac{D(1-D) R_{s} T_{s}}{N L} \\ \frac{(1-D)}{C}+\frac{I_{g} R_{s}}{C V_{0} N} & \frac{-1}{R C}-\frac{I_{g} D(1-D) R_{s} T_{s}}{C V_{0} N L}\end{array}\right] \hat{I}_{g} \hat{V}_{0}\right]+\left[\begin{array}{l}\frac{(1-D)}{L N} \\ \frac{-I_{g}(1-D)}{C V_{0} N}\end{array}\right]\left[\hat{V}_{m}\right]$

where $\mathrm{N}$ is

$\mathrm{N}=\left[\frac{V_{m}}{V_{m 0}}+\frac{V_{g} R_{s} T_{s}}{2 L V_{o}}+2 D\left(\frac{R_{s} T_{s}}{L}\right)-\left(\frac{R_{s} T_{s}}{L}\right)\right]$

The analytical model developed in this section is valid at any input-output and load condition as long as the boost converter operates in the continuous conduction mode.

In the active power factor correction converters, the input power is defined as

$P_{i n}(t)=v_{\text {in }}(t) i_{\text {in }}(t)=v_{g}(t) i_{g}(t)=\frac{v_{g}^{2}(t)}{R_{e}}=P_{i n}\left[1-\cos \left(2 \omega_{f} t\right)\right]$

From the above equation we can see that, the input power contain a low frequency component at twice of the line frequency. This low frequency ripple will appear across the output capacitor is given by

$$
\left|\Delta v_{o}(t)\right|=\frac{I_{o}}{2 \omega_{f} C_{o}} \sin \left(2 \omega_{f} t\right)=\frac{P_{o}}{2 \omega_{f} C_{o} V_{o}} \sin \left(2 \omega_{f} t\right)
$$

where $\omega_{f}$ is the line angular frequency $(\mathrm{rad} / \mathrm{s})$ and $P_{o}$ is the output power. This holds provide that the voltage loop has a bandwidth well below the line frequency [typically 20HZ].

A closed loop boost compensator for the outer voltage loop can now be designed, based on the model given by (10). The Block diagram and characteristics of proposed Boost compensator is shown in Fig. 2
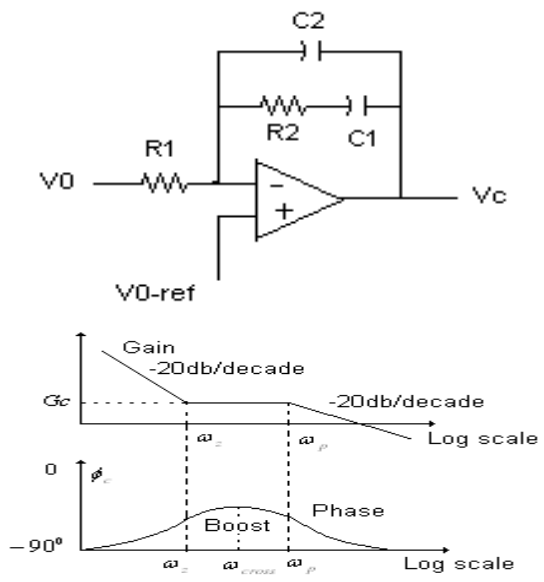

Fig.2.Boost Compensator

$$
\mathrm{T}_{\mathrm{c}}(\mathrm{s})=\frac{A}{S} \frac{S+\omega_{z}}{S+\omega_{p}}
$$

Where $\mathrm{A}=\frac{1}{R_{1} C_{1}}, \omega_{\mathrm{z}}=\frac{1}{R_{2} C_{1}}, \omega_{\mathrm{p}}=\frac{C_{1}+C_{2}}{R_{2} C_{2} C_{1}}$

Where $\mathrm{A}$ is positive and $\omega_{z}<\omega_{p}$. Due to the pole at the origin, the phase of $T_{c}(s)$ starts with $-90^{\circ}$. The presence of the zero provides a "boost" to be something greater than $-90^{\circ}$. Eventually because of the pole at $\omega_{\mathrm{p}}$, the phase angle of $\mathrm{T}_{\mathrm{c}}(\mathrm{s})$ comes back down to $-90^{\circ}$.

\section{DESIGNING OF BOOST COMPENSATOR.}

The parameters in (10) can be designed using K-factor approach[5]. The design procedure of the proposed closed loop boost compensator design for Predictive current mode controller are summarized as below:

Step1: Determine the Crossover frequency $\omega_{\text {cross }}$. The K-factor is used in (10) such that

$$
\begin{aligned}
& \omega_{z}=\frac{\omega_{\text {cross }}}{K} \\
& \omega_{p}=K \omega_{\text {cross }}
\end{aligned}
$$

$\mathrm{K}$ can be defined as $K=\tan \left(45^{\circ}+\frac{\text { boost }}{2}\right)$

Step2: Set the required closed loop PM at the Crossover frequency, and hence, the boost needed from the error amplifier to calculate $\mathrm{K}$ in equation (11) and (12) . Boost can be defined as Boost $=$ PM $-\varphi_{1}-90^{\circ}$.

$\varphi_{1}$ is the phase angle of the loop transfer function $\hat{G}_{v}(s)$ at the crossover frequency. It can be obtained from the frequency response of (8)

Step3: Find the gain $\mathrm{G}_{\mathrm{c}}(\mathrm{s})$ of the compensator at $\omega_{\text {cross }}$ by using the condition

$$
\left|G_{o l}\left(\omega_{\text {cross }}\right)\right|=1
$$

Step4: Set the value for $\mathrm{R}_{1}$

From the equations (11)-(15) rest of the parameters can be calculated as fallows:

$$
\begin{aligned}
& C_{2}=\frac{G_{1}}{K R_{1} \omega_{\text {cross }}} \\
& C_{1}=C_{2}\left(K^{2}-1\right) \\
& R_{2}=\frac{K}{C_{1} \omega_{\text {cross }}}
\end{aligned}
$$

\section{SIMULATION RESULTS}

A Predictive current mode control boost rectifier with the proposed boost compensator has been simulated. The output voltage of the rectifier is regulated at $400 \mathrm{~V}$. In this, the current sensing resistance is $1.98 \Omega$. The proposed boost compensator is designed at PM of $55^{\circ}$ with the cross over frequency of $10 \mathrm{HZ}$.The remaining circuit parameters are designed for $\mathrm{Mg}=0.59$ at $\mathrm{K}=0.15[1]$. The simulation waveforms of the input current $\left(i_{i n}\right)$, input voltage $\left(v_{i n}\right)$, at different load conditions are shown in Fig.3.(a) and (b).The harmonic spectrum of the corresponding input current is shown in Fig.3. (c) and (d). it can be seen that the PF of the boost rectifier is almost unity. The total harmonic distortion is less. The output voltage waveform is shown in Fig.3.(e) and (f) at $\mathrm{R}=350 \Omega$ and step change from $250 \Omega$ to $1000 \Omega$ at $0.5 \mathrm{sec}$ respectively. It can be seen that Peak over shoot in out put voltage under the transient condition is around $2.5 \%$ and the output voltage is regulated with low ripple factor under steadystate condition. 


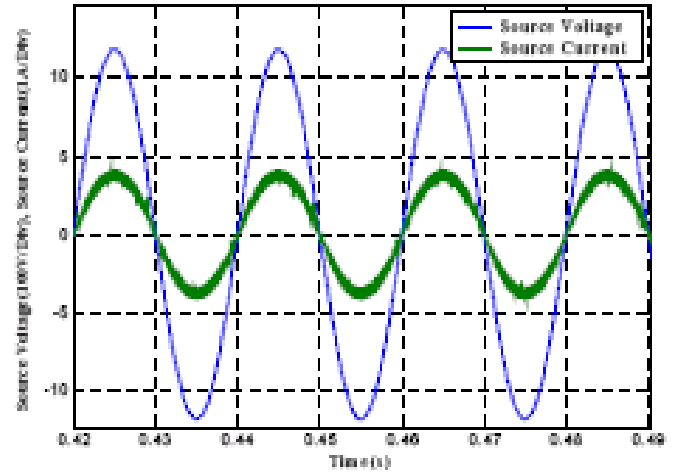

(a)

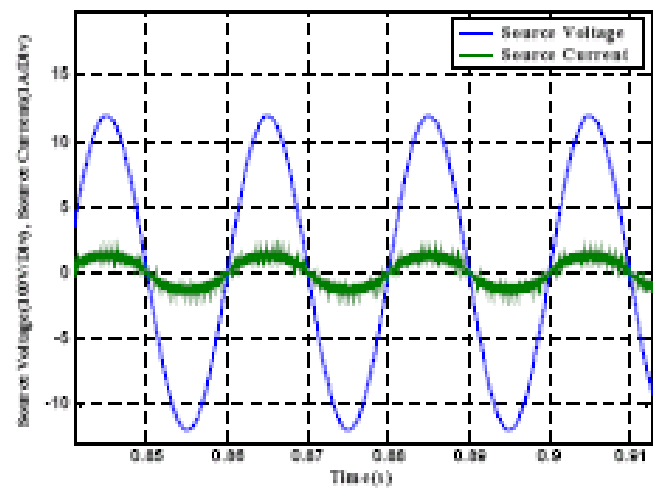

(b)

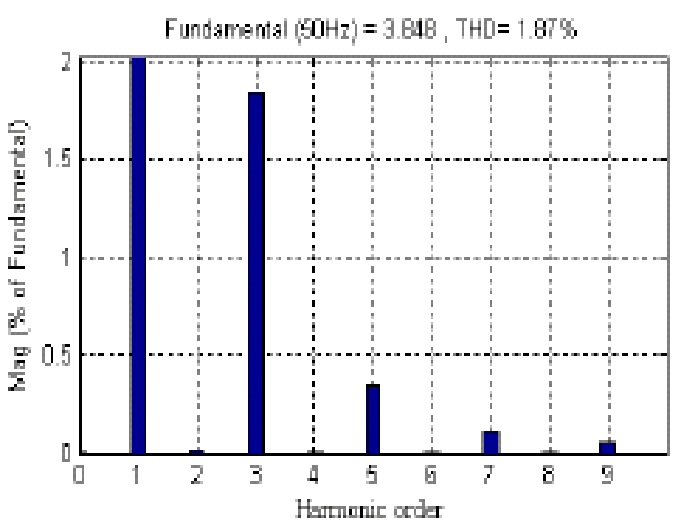

(c)

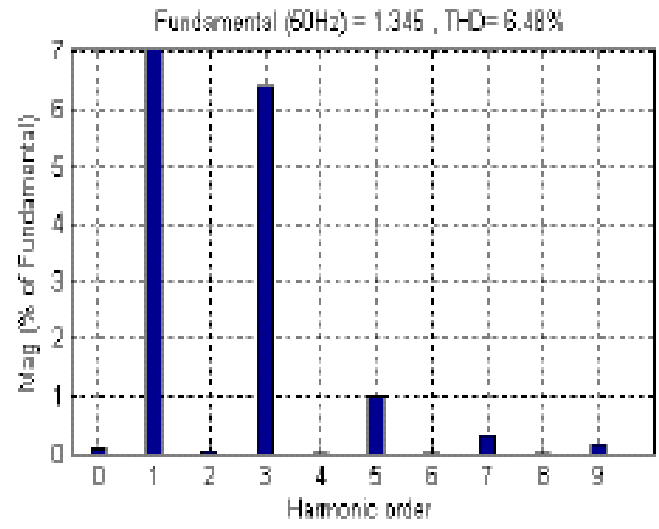

(d)

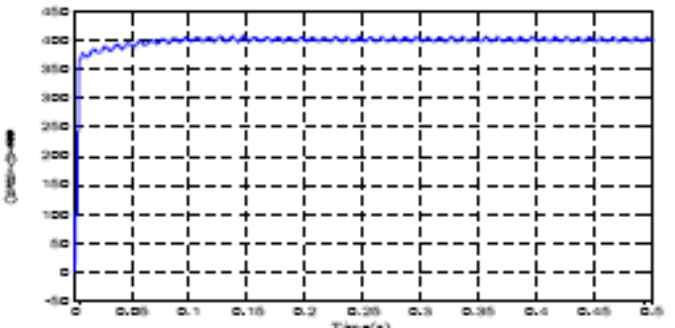

(e)

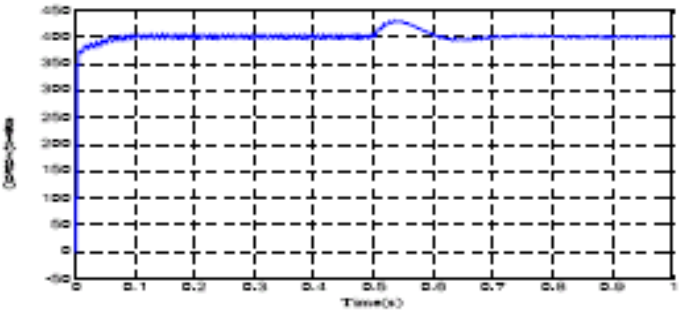

(f)

Fig.3.Simulation results: (a),(b) are input current and voltage,(c),(d) are THD in input current, (e) and (f) are output voltage at $\mathrm{R}=350 \Omega$ and $\mathrm{R}=250 \Omega-1000 \Omega$ at $0.5 \mathrm{sec}$ respectively

\section{CONCLUSION}

In this paper, a boost compensator for Predictive current mode control high power factor boost rectifier has been proposed. The controller implements the switching function in such a way that the actual current lies on the top of a reference current profile that has the same shape as the input voltage waveform. This is achieved without sensing of the input voltage and the use of the multiplier in the controller circuit. The inputs at the nominal operating point of input voltage rms. Very low THD in the input current and tight voltage regulation obtained over a wide range of loads

\section{REFERENCES}

[1] .V.Ramanarayanan, SouvikChattopadhyay,.Jayashankar, "A Predictive switching modulator for current mode control of High Power Factor Boost Rectifier" IEEE Transactions on Power electronics, Vol 18,PP.114-123, January 2003

[2] . R. Zane and D. Maksimovic', 'Nonlinear carrier control for high-power-factor rectifier based on up-down switching converters", IEEE Trans. Power electron., Vol.13,PP.213221,Mar.1998

[3]. F.Dong Tan and R.D. Middlebrook, "A unified Model For Current -Programmed-Converters", IEEE Trans. PowerElectron., Vol. 10, pp.397-408, July 1995.

[4]. R.D.Middlebrook and S.M.C'uk," A general unified approach to modeling switching converter power stages," in proc. IEEE PESC'76 Conf., 1976,pp.18-34

[5]. H.Dean venable, "The K-Factor; A new mathematical tool for stability analysis and synthesis," proceeding of powercon 10, Sam Diego, CA, march 22-24,1983. 


\section{Biographies}

K.Ramalingeswara Prasad was born in India. He received the B. Tech from the Department of EE engineering Nagarjuna University. And M.Tech from the Department of Electrical Engineering, Govt.College of Engineering, Pune,India. He worked as R\&D Engineer in Amararaja Power systems, Karakambadi, Tirupathi form Aug 2005 to July 2006 presently working for Lakireddy Bali Reddy College of Engineering as Asst.Professor in the Department of Electrical Electronics Engineering, Mylavaram.His research interests include ac-dc converter with power factor correction, SMPS and Active power filters for Harmonic compensation.

P.Deepak Reddy was born in India. He received the B. Tech from the Department of EE engineering JNTU. And M.Tech from the Department of Electrical Engineering, VIT, Vellore India.
Presently working for Lakireddy Bali Reddy College of Engineering as Asst.Professor in the Department of Electrical Electronics Engineering, Mylavaram.His research interests include ac-dc converter with power factor correction, SMPS and Active power filters for Harmonic compensation.

Kranthi Kiran. Ankam was born in India. He received the B. Tech from the Department of EE engineering JNTU. And M.Tech from the Department of Electrical Engineering, Gayathri Vidya Parishat. India. presently working for Lakireddy Bali Reddy College of Engineering as Asst.Professor in the Department of Electrical Electronics Engineering, Mylavaram. His research interests include ac-dc converter with power factor correction, SMPS and Active power filters for Harmonic compensation. 